\title{
Car Seat-Belt Regulations, Offsetting Behaviour, and Liability Rules
}

\author{
Alan Woodfield
}

7 HE joys of motoring are not free, and come partly at the expense of injuries to motorists and others. Many regulations compel motorists to adopt safety features. The widespread mandating of seat-belt installation and wearing in passenger cars is a clear example. New Zealand mandated seat-belt installation for new cars in 1965, compulsory wearing in 1972, and compulsory installation in all post1955 cars in 1975 . Initially, only 16.7 per cent of drivers who had belts installed were observed to wear them; this figure rose to 39.5 per cent by May 1972, and more than doubled by May 1975 (Toomath \& Laurenson, 1976:Table 1). Then followed the progressive introduction of lowered ages for child belt-users, requirements for belt-use by rear-seat passengers, and the use of child restraints. Survey data from New Zealand's Land Transport Safety Authority, however, indicated that, of vehicle occupants killed in crashes in 1989-95, only 32 per cent wore belts, while 33 per cent were 'uncertain' cases.

In the United States, only 11 per cent of car occupants used belts following mandatory installation in 1966. Although the use rate had increased to 26 per cent by 1974 , it had fallen to only 14 per cent by 1983 , when state belt-wearing laws emerged (Crandall et al., 1986:54). By 1987, however, only 31 states had such laws. Partly in consequence, the Intermodal Surface Transportation Efficiency Act 1991 requires all 1998 model-year passenger cars to have air bags and manual lap/shoulder belts for both drivers and front-seat passengers.

\section{Seat-Belt Use and Offsetting Behaviour}

The joys of safety are also not free. A rational person might choose not to purchase a seat-belt or, having purchased it, not to wear it at all times. Although people value a safer driving environment, the annual probability of suffering a serious injury is extremely low even without seat-belt protection.' People are unwilling to pay much to reduce low levels of risk further. Although seat-belts seem inexpensive, their costs are not necessarily trivial relative to their benefits. In addition to purchase and installation costs, they involve time and inconvenience costs. As well, while seat-belts reduce

\footnotetext{
'See for example Arnould and Grabowski (1981:Table 1). The authors note that the expected reduction in annual risk from wearing a seat-belt is of the order of $0.0001-0.00001$.
}

Alan Woodfield is Senior Lecturer in Economics at the University of Canterbury. 


\section{Alan Woodfield}

head-on collision risks, they may be counterproductive in side-impact collisions, or where fire or water is present in an accident and egress is impeded.

Even if seat-belts are worn, their potential for risk reduction may be limited. Drivers' behaviour may depend on the level of safety available. The Offsetting Behaviour Hypothesis $(\mathrm{OBH})$ predicts that drivers who use a higher level of safety features will respond by driving in a riskier manner, such as by increasing speed, drinking and driving more frequently, driving in more hazardous conditions, and taking less care.

Some commentators deny this. Motoring correspondent Dave Moore argued that "when seat belts were first made available on the world's markets, there were those who contended that . . . drivers who wore seat belts were likely to drive carelessly with the false sense of security imparted by the equipment', and considered that 'most of us today would regard that as nonsense' (Christchurch Press, 24 November 1995). Yet most of 'us' would agree that we reduce speed and pay more attention in increased traffic density or adverse weather conditions. It surely follows that drivers can be expected to drive with less care and attention when they are protected by better safety features.

\section{Evidence of Offsetting Behaviour}

Risks associated with offsetting behaviour will be borne partly by drivers. If a driver wears a seat-belt, the probability of serious injury or death in an accident is reduced. But if wearing a seat-belt induces greater speed, this will in itself raise the probability of an accident in the first place and will also raise the magnitude of harm suffered. Further, unprotected passengers and non-occupants face greater risks and more serious harms.

But is the $\mathrm{OBH}$ empirically important? A considerable literature suggests that $\mathrm{OBH}$ effects are ignored at society's peril. Most studies are heavily influenced by Peltzman (1975). The basic procedure specifies an equation to explain the determinants of observed injuries involving passenger vehicles (usually fatalities or fatality rates per unit of distance travelled) in terms of a set of explanatory variables. Injury rates typically include some combination of total, driver, occupant, passenger, and nonoccupant injuries, the latter frequently broken down by pedestrians, bicyclists and motorcyclists. Explanatory variables typically include an index of safety of the vehicle stock, average income, average alcohol consumption, youth, the relative price of petrol, vehicle speed, and the uninsured components of the costs of repairs. Some studies also include speed limits, safety inspection requirements, climatic factors and the like; and speed is sometimes treated as endogenous.

Surveys may be found in Blomquist (1988) and Woodfield (1995). Here, only results specifically dealing with seat-belts are considered: Evans and Graham (1991) and Garbacz (1990, 1992a, 1992b) for the US, Garbacz (1991) for New Zealand, and Risa (1994) for Norway.

For the US, Evans and Graham pooled data from 50 states. They concluded that while seat-belt laws reduced fatalities among car occupants, there was weak evidence that fatalities of non-occupants increased. Garbacz (1992a), however, using state crosssectional data, found that seat-belt laws generated no statistically significant effects for 
overall and occupant fatalities, while raising the non-occupant fatality rate, and suggested that reduced fatalities for drivers may be offset by increased fatalities for passengers. Garbacz (1992b) found that where primary enforcement seat-belt laws held (that is, where tickets can be directly issued for a violation), rear-seat passenger and non-occupant fatalities were greater, although there was no similar statistically significant effect for states with secondary enforcement laws (where tickets can be issued only if there has been a non-belt-related violation). With primary enforcement, the probability of apprehension (and hence the size of the expected penalty) for violation is higher than for secondary enforcement. A larger proportion of drivers in primaryenforcement states would be expected to wear belts and drive less carefully, exposing unbelted passengers and nonoccupants to greater risks. Further, Garbacz (1990) found that self-reported seat-belt usage had no significant effect for overall fatalities, overall occupants, or drivers, while passenger and non-occupant fatalities increased. He further examined (1992b) the result for passengers, finding that the harmful rear passenger effect exceeded the beneficial front (belt-wearing) passenger effect.

For New Zealand, using time-series data from 1960-85, Garbacz (1991) found that offsetting behaviour may have offset the effectiveness of seat-belt laws in reducing road fatalities. Like Toomath and Laurenson (1976) and Hurst (1979), Garbacz found significant favourable effects on car occupants. However, Garbacz found that these effects were offset, perhaps more than completely, by increased fatalities of nonoccupants. The favourable effect on occupants was also found to be below average compared with other studies, a point also noted by Toomath and Laurenson when comparing the immediate post-compulsory belt-wearing period in New Zealand with some Australian States.

For Norway, Risa (1994) used a pooled annual time series of cross-sections of 18 counties, and included non-fatal injuries as well as fatalities. While injury severity was not measured, Risa obtained the most unusual result of a statistically significant positive effect of the level of seat-belt compliance on drivers, as well as significant adverse effects on all other road users within densely populated areas.

Although these results are not uniform, and some are not very robust, it seems reasonable to conclude that, on balance, increased seat-belt use provides additional safety protection for occupants (although rear-seat passengers may be exposed to greater risks, and even drivers may face greater risks of minor injury), while nonoccupants are exposed to greater injury risks as a result of increasingly risky behaviour of drivers. The unfavourable effects for non-occupants $\underset{3}{3}$ far from numerically trivial, and may even exceed the favourable effect for drivers.

\footnotetext{
${ }^{2}$ There is also conflict in some Australian evidence. For example, Swan (1984) found that belt installation generated a large reduction in fatalities, whereas McEwin (1986) found no such similar effect. 3

In a recent paper, Peterson, Hoffer and Millner (1995) also found significant offsetting behaviour when cars are equipped with air bags.
} 


\section{Should Seat-Belts be Mandatory?}

Should the government intervene in the market for safety equipment, and in the market for seat-belts in particular? Assuming that buyers of seat-belts are properly informed about their true characteristics and their ability to attenuate risks, if drivers bore their own damage costs, and if accidents involved only drivers colliding with valueless stationary objects, there would seem little reason to compel people to wear seatbelts. Even if a person elects to wear a belt, and as a result speed increases, there seems to be no obvious case for intervention. Drivers will weigh up the benefits of belts, taking account of any behavioural adjustments, and use them if these benefits exceed the combined costs of their purchase, fitting, and inconvenience. Benefits to drivers include the change in their expected accident costs plus the value of their time savings if offsetting behaviour occurs and drivers increase their speed.

Suppose a driver is unwilling to pay these costs. Why force her to do so? A major argument is that motorists are poorly informed about risks or are not competent to make rational assessments of safety decisions, particularly when faced with lowprobability events with serious consequences (see, for example, Kunreuther, 1976). Accumulating evidence, however, suggests that people are not incompetent in assessing situations with different costs and benefits of seat-belt use. Blomquist (1977) examined 1,800 US drivers and found that the likelihood of use was clearly increasing in their perceived net benefits. McCarthy (1986) and Winston (1987) found that drivers used belts more when their vehicles or travel environments became more risky. Blomquist (1991) analysed 8,312 US drivers and found belts used more frequently by the more highly educated (whose opportunity cost of damaging human capital is relatively high), by those driving lighter cars and by those facing greater driving hazards, but less frequently by those with greater use costs such as short trips where inconvenience costs cannot be spread over much distance.

These studies may be unable to establish fill risk competence. But if politicians and regulators remain convinced that drivers underestimate risks, why do they not provide motorists with their (allegedly) superior information, and maintain individual choice regarding safety decisions? Of course, politicians could not then be captured by producer interests like the manufacturers of safety equipment.

\section{Externalities and Liability Rules}

A different argument is based on externalities. Many collisions involve harm to others. Passengers in a driver's vehicle may be injured or killed. Here, there are strong incentives to negotiate driving risks. Cautious husbands will try to contain the speed of 'milk-toast turned daredevil' wives. However, strangers (parties to potential accidents for whom it is prohibitively costly to negotiate risk reductions) are also exposed to these risks. If seat-belt laws encourage less careful driving, strangers are exposed to greater hazards without any compensating benefits.

The behaviour of drivers, however, and the resulting impact on third parties, will be influenced by the law of liability. Consider the three liability rules of zero liability, 
negligence and strict liability. A key argument is that the negligence and strict liability rules give drivers an incentive to internalise the external costs imposed on others.

Suppose that the accident rate and accident severity depend only on the behaviour of participants to an accident, and that injurers and victims are neutral with respect to risk (and so have no incentive to purchase insurance). Payoffs are assumed to possess monetary equivalents. Consider a simplified situation. Let accident victims take a given level of care. For instance, a 'representative' motorcyclist (M) may elect to wear a helmet, and travel at a given speed. Suppose that in the event of a collision with a car, a motorcycle is damaged and the rider is injured but can be 'restored' to the pre-accident health status at a cost. Suppose further that the car is damaged and the 'representative' driver $(C)$ suffers injuries, but can be 'restored' at a cost. Finally, assume that the driver can either drive 'slow' (in which case the probability of an accident is relatively small) or drive 'fast' (in which case the accident probability is relatively high). Let $\mathrm{C}$ always cause the accident, and suffer moderate damage if travelling fast, and minor damage if travelling slow. $M$ suffers moderate damage if struck at low speed, and serious damage if struck at high speed. Both parties get a 'basic' payoff (net of transportation costs) from each trip, while $\mathrm{C}$ gets an additional payoff if she drives fast, measuring the value of her time savings.

Each of the three liability rules specified above is now analysed under the following three scenarios: seat-belts unavailable; seat-belts available but not mandatory; and seat-belts mandatory.

\section{Liability with Seat-belts Unavailable}

Zero liability. Under zero liability, the driver does not compensate the motorcyclist in the event of an accident, but has to bear her own damages, as does the motorcyclist. The driver's best response is to choose a speed that maximises her expected payoff (hereafter 'payoff'). She will drive fast if the value of her time savings exceeds the corresponding increase in expected accident costs (hereafter 'accident costs') that she herself suffers. The motorcyclist has no effective choices to make, given that the trip occurs. His payoff is smaller if $\mathrm{C}$ drives fast, since he is more likely to suffer an accident, and a more serious accident, than if she drives slow.

The total net benefit under each regime is as follows: (i) $\mathrm{C}$ drives slow, so that the net payoff to society equals the 'basic' payoff to each party less the damages to both parties when $\mathrm{C}$ elects to drive slow; (ii) $\mathrm{C}$ drives fast, in which case the net payoff to society equals the 'basic' payoff to each party, plus the value of C's time savings from fast travel, minus the damages to both parties when $\mathrm{C}$ drives fast. Suppose that $\mathrm{C}$ drives fast. Total net benefits are maximised if the value of the gains in terms of time savings to $\mathrm{C}$ exceeds the additional damages to both parties resulting from her decision to drive fast. This condition may not be satisfied in practice, and while it may pay $\mathrm{C}$ to drive fast from her own viewpoint, it is in society's overall interest for her to drive slow, since the value of her time savings fails to compensate for the additional accident costs that both parties must bear. Here, the zero liability rule is inefficient.

But what if C elects to drive slow? She will do so if the value of her time savings is less than the increase in accident costs that she must bear. If she drove fast, socicty 
would be worse off on two counts. First, C's own additional accident costs are undercompensated by the value of her saved time. Second, $M$ must suffer greater (uncompensated) damages when $\mathrm{C}$ drives fast. It will always be in society's interest for C to drive slow if she chooses to do so.

Negligence. Under the negligence rule, a driver deemed negligent is required to compensate the motorcyclist in the event of an accident caused by the driver. The courts must set a standard of due care to determine whether a driver has been negligent. From an efficiency viewpoint, the courts should set the due care standard such that the additional costs of taking further care do not exceed the additional benefits.

Suppose that meeting this standard involves C's driving slow, and that it has been appropriately set in that the incremental cost to society (given by the loss in the value of C's time savings) is less than the incremental benefits (given by the savings in expected accident costs to society as a whole when $\mathrm{C}$ travels slow rather than fast). This, however, is just the condition for slow driving by $\mathrm{C}$ to be socially optimal.

The question, however, is whether $\mathrm{C}$ will choose to drive slow under the negligence rule. She drives slow if the value of her time savings is less than the increase in her own accident costs plus the total accident costs to $M$ when she drives fast. But if the condition for the social optimality of slow driving is satisfied, the condition for the private optimality of slow driving must also be satisfied. A speeding driver deemed negligent must pay for the total damages to the motorcyclist and bear her own damages, whereas she pays no damages to the motorcyclist if she drives slow and causes an accident. Since we know that the value of C's time savings is less than the change in damages to both parties, these time savings must also be valued less than the change in C's damages plus M's total damages (as opposed to the change in M's damages). Hence, the negligence rule is efficient in this case.

Strict liability. Under strict liability, a person causing an accident must compensate the victim whether or not she was at fault. Consider the motorist's decision whether or not to drive fast. $\mathrm{C}$ will choose to drive slow if the value of her time savings is less than the increase in society's accident costs generated by her fast driving. But this is just the condition for the social optimality of slow driving. Similarly, privately optimal fast driving would also be socially optimal. Strict liability is an efficient legal rule in this case.

\section{Liability with Voluntary Seat-belts}

Zero liability. Suppose that seat-belts become available, and their use is voluntary. If wearing a belt, motorists suffer less damage to themselves at each of the two speed levels chosen. The motorist must now jointly decide (i) whether to buy a belt, and (ii) whether to drive slow or fast. Suppose that the various monetary and psychic costs of buying and wearing belts are aggregated as 'resource costs'; and let $\mathrm{C}$ drive slow prior to seat-belt introduction. The $\mathrm{OBH}$ suggests that the belted driver will speed up. Under zero liability, it will pay $C$ both to buy a belt and to drive fast if the value of her 
time savings exceeds the change in her accident damages plus the resource costs of belt-wearing.

Social optimality of fast driving with a belt instead of slow driving without a belt implies that the value of C's time savings exceeds the change in accident costs to both parties combined plus the resource costs of the belt. If it is socially optimal for $\mathrm{C}$ to drive fast, it is certainly privately optimal for her to do so. However, the converse is not necessarily true. If the value of C's time savings is less than the change in accident costs to both parties combined plus the costs of the belt, $\mathrm{C}$ should drive slow. But it pays $\mathrm{C}$ to purchase a belt and drive slow only if the cost of the belt is less than her increased accident costs when she drives slow while not wearing a belt. Note than $M$ is unaffected by this decision, since $\mathrm{C}$ is driving slow in any case. But this is just the condition for $\mathrm{C}$ to choose to wear a belt and drive slow. So a decision by $\mathrm{C}$ to buy $\mathrm{a}$ belt, given that she drives slow, is also socially optimal.

However, the question is whether it will pay $\mathrm{C}$ to buy a belt and drive fast, which is not socially optimal. She will do so if the value of her time savings exceeds the difference between her accident costs when driving fast and wearing a belt and her accident costs when driving slow and wearing a belt. This result is certainly possible. Yet we want $\mathrm{C}$ to buy a belt and drive slow. She will voluntarily buy the belt, but she will not voluntarily drive slow. We do not want to deter her from buying the belt, but we wish to induce her to keep her speed down. Given adherence to zero liability, taxing seatbelts would be a poor idea. Instead, we want to penalise fast driving, which can be achieved by setting an expected fine for high speed travel so as to make $\mathrm{C}$ marginally prefer to buy a belt and drive slow. The expected fine should equal the difference between the value of time savings from fast driving and the change in the expected damages to $\mathrm{C}$ when she straps on her belt and then speeds up.

Negligence. Again assume that it was previously privately (and socially) optimal for C to travel slow, and that C's best option under zero liability is to buy a belt and drive fast. However, suppose also that the value of her time savings is less than the cost of belt purchase plus the change in accident costs to society as a whole. Then, she should drive slow without a belt. Zero liability is inefficient here. But suppose the rule was that of negligence. How would the courts decide on the socially optimal level of due care? They should again follow the principle of comparing the costs of taking care (driving at a low speed and losing time) with the benefits of taking care (the savings in accident costs to society when $\mathrm{C}$ drives slow rather than fast). But since $\mathrm{C}$ would not purchase a belt when she drives slow, the courts should also give consideration to the cost of belts which attenuate the damage faced by $\mathrm{C}$ in an accident at any given speed.

Recall that $\mathrm{C}$ should drive slow from society's perspective because net social benefits are maximised when she drives slow without a seat-belt rather than driving fast while belted. The courts should account for the resource costs of the belt here, since if they are treated as zero, the positive impact of the expenditures in keeping damages to the motorist at a relatively low level when speed increases will have been ignored. Otherwise, travelling fast may erroneously be believed to be socially optimal. The 
irony is that, to induce the motorist to take the appropriate level of care, we want her to reduce her purchases of safety equipment.

The negligence rule makes $\mathrm{C}$ liable for damages suffered by $\mathrm{M}$ when she drives fast and causes an accident. $C$ drives slow without a belt if the value of her time savings less the resource costs of the belt is less than the increase in her own accident costs plus total accident costs to $\mathrm{M}$ when she drives fast when belted. But we know from setting the socially optimal level of due care that this condition must be satisfied, since the value of C's time savings minus the resource costs of the belt is less than her own increase in accident costs plus the increase in accident costs to $M$ when she drives fast when belted. In these circumstances, if seat-belts are voluntary, the negligence rule will always induce a driver who would purchase a belt and drive fast to drive slow and forgo the purchase of a belt, which is the socially optimal result.

Strict liability. Under strict liability, C will neither buy a belt nor speed up if the value of her time savings is less than the cost of a belt plus the change in total accicient costs when she is driving fast while wearing a belt compared with driving slow without a belt. But this is just the condition for it to be socially optimal for her to continue to travel slowly without wearing a seat-belt. Thus, privately optimal decisions under strict liability are also socially optimal decisions. Strict liability is an efficient legal rule, as was the negligence rule. There are no differences with respect to incentives. The only difference is that $\mathrm{C}$ must always compensate $\mathbf{M}$ under strict liability if she causes an accident.

\section{Liability with Mandatory Seat-belts}

Zero liability. Now let seat-belts become available, and their use mandatory. Assume that $\mathrm{C}$ drives slow prior to belt availability, and that, under zero liability, sie would choose not to purchase a belt if available. This implies (i) that belt costs erceed the reduction in accident costs to $C$ when she wears a belt when driving slow, and (ii) that the value of time savings is less than the change in C's accident costs when she both buys a belt and speeds up, plus the costs of buying a belt. Thus, she will not buy a belt unless required, and without a belt she will drive slow. If belt purchase and wearing is compulsory, what will she do? Under zero liability, she drives fast if the value of her time savings exceeds the change in her own accident costs arising from her diving fast rather than slow when wearing a belt.

Conditions (i) and (ii) above will be jointly satisfied if the cost of the bet plus the change in C's accident costs when she belts up and drives fast compared wih driving slow without a belt exceed the change in C's accident costs when she is committed to wearing a belt and elects to drive fast rather than slow. But this is just the situation where $C$ decides to travel slow without a belt rather than with a belt.

Consequently, we have the intriguing situation where, in the absence of seat-belts, C's decision to drive slow is both privately and socially optimal, and when seat-belts become available, it is both in her and society's interest for her not to wear one. If she is now forced to wear a belt, her best response is to speed up, raising M's accident 
costs, which is not socially optimal. Since C is not liable for M's additional accident costs, $\mathrm{C}$ has no incentive to continue to drive slow when belted-up.

In New Zealand, the post-1972 belt-wearing requirement was accompanied by a move from a negligence rule to that of a public no-fault accident compensation scheme. This change in incentives provides a good reason why Garbacz (1991) found stronger offsetting behaviour effects for New Zealand than elsewhere, although the issue is complicated by the fact that motorists injured by the negligence of others were no longer fully compensated for their losses, and would be expected to drive more carefully on this account.

Negligence. Under the negligence rule, suppose the courts maintain the same principle for setting the due care standard as when selt-belts were voluntary. $\mathrm{C}$ will now drive fast rather than slow if the value of her time savings are greater than the change in her own accident costs when wearing a belt and speeding up, plus M's total accident costs. The cost of the seat-belt is irrelevant to her decision, since it is (effectively) sunk. The point is whether this condition can hold at the same time as the condition which is used by the courts in deciding whether or not fast driving constitutes negligence. The requirement is that the resource costs of the belt exceed the total accident costs to society when $C$ drives slow without a belt, minus the accident costs to $C$ when she drives slow when wearing a belt. This can clearly hold, and so what appears to be a correctly set negligence rule fails to deter fast driving under mandatory seat-belt wearing where it is not socially optimal for fast driving to occur. Further, attempting to save the negligence rule by setting exemplary damages so that $\mathrm{C}$ marginally prefers to drive slow while weaning a belt is inferior to the repeal of the mandatory belt requirement.

Suppose that it pays $\mathrm{C}$ to drive fast under the negligence rule, while it is socially desirable for her to drive slow, but without a seat-belt. Given that she must wear a belt, however, it is better for society to permit her to be 'negligent' and drive fast if the value of her time savings exceeds the resulting increase in society's accident costs. Additional damages would be appropriate only if the social payoff to her driving fast while wearing a belt were less than when she drives slow when belted, even though the best outcome is for $\mathrm{C}$ to drive slow without a belt. Thus the courts might first believe (wrongly) that they are imposing an optimal level of damages in designing the due care standard, and then compound the error by imposing exemplary damages.

Now take the case where the value of C's time savings exceeds the increase in total accident costs when $\mathrm{C}$ elects to drive fast rather than slow when wearing a seat-belt. Again, let the conditions for the apparently optimal standard of due care be set and assume that the motorist is deemed negligent if she drives fast. These circumstances will coexist if the belt cost exceeds the increase in damage to $\mathrm{C}$ when she drives slow without a belt compared with when she does wear one. However, let $\mathrm{C}$ prefer to drive slow rather than fast when wearing a belt under this negligence rule. The rule now induces $\mathrm{C}$ to drive slow while wearing a belt which she is legally obliged to wear. The socially optimal outcome is for her not to wear a seat-belt and to drive slow, which she will do voluntarily. If she must wear a belt, she will drive slow under the negligence 
rule. Unfortunately, in this example, it is in society's interest for her to drive fast! The negligence rule would then require correction by imposing negative exemplary damages so that $\mathrm{C}$ marginally prefers to drive fast when forced to wear a belt. This is hardly an intuitively appealing result.

Strict liability. With strict liability, C will drive slow rather than fast when forced to wear a belt if the value of her time savings is less than the increase in total accident costs when wearing a belt and travelling fast rather than slow. Suppose this condition is satisfied. Society is then also better off if she drives slow while wearing a belt. Thus, privately desirable slow driving will be socially desirable, and, similarly, privately optimal fast driving will also be socially optimal. But it is still the case that society is better off not mandating seat-belts if the resource costs of the belt exceed the value of C's time savings minus the change is society's expected accident costs when she switches from slow driving without a belt to fast driving with a belt.

Thus, strict liability will be a more efficient liability rule than zero liability in general, and will also be more efficient that the negligence rule if courts do not properly account for the fact that seat-belt costs no longer enter the private calculus of drivers and that the level of expected accident costs when not wearing a belt now becomes an irrelevance. However, no legal rule can be designed to compensate for inefficient regulation involving mandating safety equipment which offers society as a whole insufficient additional protection to be worth its costs when offsetting behaviour is properly accounted for. In fact, it might pay a society that has mandated the use of seat-belts to devote no resources to enforcement, since drivers who refuse to wear belts will not speed up as a consequence of having a belt available, but not worn.

\section{Conclusion}

Empirical evidence suggests that car seat-belts are a mixed blessing in that gains to driver safety are significantly offset by greater risks and more serious injuries suffered by others when drivers speed up or take less care when belted-up. Because of offsetting behaviour, engineering estimates of safety gains from seat-belt use may be quite misleading. The extent of offsetting behaviour is affected by society's choice of liability rule applied to motor vehicle accidents (and also by the presence and characteristics of insurance markets, which are not discussed here). Zero liability provides no incentive to account for additional risks imposed on others, whereas the negligence or strict liability rules have desirable incentive properties, especially in the absence of contributory negligence by victims of accidents. However, if seat-belt use is mandatory when not cost-effective, the negligence rule may lose its desirable incentive properties if courts continue to set the standard of due care on what otherwise appears to be an efficient principle. While strict liability retains its desirable properties, no liability rule can fully compensate for a mandated safety device for which the costs to society as a whole are less than benefits.

${ }^{4}$ Strict liability and negligence are not generally incentive-equivalent. For instance, if motorcyclists can increase their level of care, strict liability gives them no incentive to do so. 


\section{References}

Amould, R. \& H. Grabowski (1981), 'Auto safety regulation: an analysis of market failure', Bell Journal of Economics 5: 27-48.

Blomquist, G. (1977), 'Economics of safety and seat-belt use', Journal of Safety Research 9: 179-89.

- (1988), The Regulation of Motor Vehicle and Traffic Safety, Kluwer, Boston.

- (1991), 'Motorist use of safety equipment expected benefits or risk incompetence', Journal of Risk and Uncertainty 4: 135-52.

Crandall, R., H. Gruenspecht, T. Keeler \& L. Lave (1986), Regulating the Automobile, The Brookings Institution, Washington DC.

Evans, W. \& J. Graham (1991), 'Risk-reduction or risk compensation: the case of mandatory safety-belt use laws', Journal of Risk and Uncertainty 4: 61-73.

Garbacz, C., (1990), 'Estimating seat belt effectiveness with seat belt usage data from the Centers for Disease Control', Economics Letters 34: 83-88.

(1991), 'Impact of the New Zealand seat belt law', Economic Inquiry 29: 310-16.

_ (1992a), 'More evidence on the effectiveness of seat belt laws', Applied Economics 24: 313-15.

- (1992b), 'Do front-seat belt laws put rear-seat passengers at risk?', Population Research and Policy Review 11: 157-68.

Hurst, P. (1979), 'Compulsory seat-belt use: further inferences', Accident Analysis and Prevention 10: $27-$ 33.

Kunreuther, H. (1976), 'Limited knowledge and insurance protection', Public Policy 24: 227-61.

McCarthy, P. (1986), 'Seat-belt usage rates: a test of Peltzman's hypothesis', Accident Analysis and Prevention 17: 425-38.

McEwin, R. (1986), No Fault and Motor Vehicle Accidents, Centre of Policy Studies, Monash University, D105, September, 1-30.

Peltzman, S. (1975), 'The effects of automobile safety regulation', Joumal of Political Economy 83: 67725.

Peterson, S., G. Hoffer \& E. Millner (1995), 'Are drivers of air-bag equipped cars more aggressive? A test of the offsetting behaviour hypothesis', Jounal of Law and Economics 38: 251-64.

Risa, A. (1994), 'Adverse incentives from improved technology: traffic safety regulation in Norway', Southem Economic Joumal 38: 844-57.

Swan, P. (1984), 'The economics of law: economic imperialism in negligence law, no fault insurance, occupational licensing and criminology', Australian Economic Review (3rd quarter): 92-108.

Toomath, J. \& C. Laurenson (1976), Evaluation of the New Zealand Compulsory. Seat Belt Legislation, Ministry of Transport, Road Transport Division, Wellington (Traffic Research Report No. 17). 


\section{Alan Woodfield}

Winston, C. \& Associates (1987), Blind Intersection: Policy and the Automobile Industry, The Brookings Institution, Washington DC.

Woodfield, A. (1995), "Automobile safety regulation: differences in utilisation of compulsory and voluntary measures and New Zealand and Uniced States liability rules', paper delivered to an IPA/CAE conference and seminar on risk, regulation and responsibility held by the Institute of Public Affairs and the ANU's Centre for Applied Economics, Sydney, July 13-14.

The author acknowledges the helpful suggestions of two referees, but is responsible for what remains. 